\title{
Evaluation of Job-Involvement and its Related Factor Among Emergency Medical Technician in Kurdistan Province in 2019
}

\begin{abstract}
Introduction: Job involvement is a prominent and effective factor in shaping employee's motivation that reflects the passion and attitude of the person to work. The aim of this study was to investigate the job involvement and its related factors in the emergency medical staff of Kurdistan province.

Methods: In this descriptive-analytic study in 2019, 100 medical emergency staff in Kurdistan province were selected through cluster sampling. Data were collected by the Kanungo questionnaire (JIQ). To analyze the information, we used version 12 of STATA software. Nonparametric Mann-Whitney, KruskalWallis, and Spearman correlation coefficients were used to evaluate the hypothesis of the study.

Results: Most of the participants were in the age range of 26-30 years old. Most of the participants had an associate degree and work experience of fewer than 5 years. Job involvement was higher in single groups in comparison to married colleagues. There was a significant relationship between job involvement, education, and marital status $(p<0.05)$. There was no statistically significant relationship between variables such as age, job experience, and income with job involvement $(\mathrm{P}>0.05)$.

Conclusion: We concluded that job involvement in the emergency medical personnel is low. So, rooting and accurate planning by the relevant managers is recommended to promote and increase job involvement.
\end{abstract}

Keywords: Job Involvement, Emergency Medical Technician, Occupational Health

\footnotetext{
Affiliations

1- Instructor, Nursing department, faculty of medicine, Kumar University of science and technology, Sulaymaniya, Kurdistan, Iraq.

2- Department of nursing, faculty of nursing and midwifery, Kurdistan university of medical sciences, Sanandaj, Iran.

3- Social Determinants of Health Research Center, Research Institute for Health Development, Kurdistan University of Medical Sciences, Sanandaj, Iran.

4. Department of Emergency Medical Sciences, faculty of paramedical, Kurdistan university of medical sciences, Sanandaj, Iran.

Corresponding Author: Ar.bio67@gmail.com
}

Article Info

Authors:

Abdi $\mathrm{K}^{1}$ 우

Yaghobi $\mathrm{M}^{2}$ 우

Nouri B ${ }^{3}$ 우

Karimian $\mathrm{A}^{4 *} \cdot$

Received: 2020.10.12

Accepted: 2020.11.11

E-Published: 2020.12.01

\section{Citation Subjects:}

Occupation, Profession, Career, Paramedics, Emergency, Technicians, Health Personnel, Occupational Safety, Industrial Hygiene, Industrial Health, Employee Health 
فصلنامه يرستار و يزشك در رزم / پاييز 99 / سال هشتم

\section{بر رسى ميزان دلبستكى شغلى و عوامل مرتبط با آن در كاركنان فوريتهاى يزشكى استان

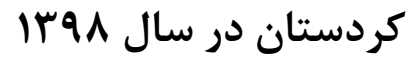

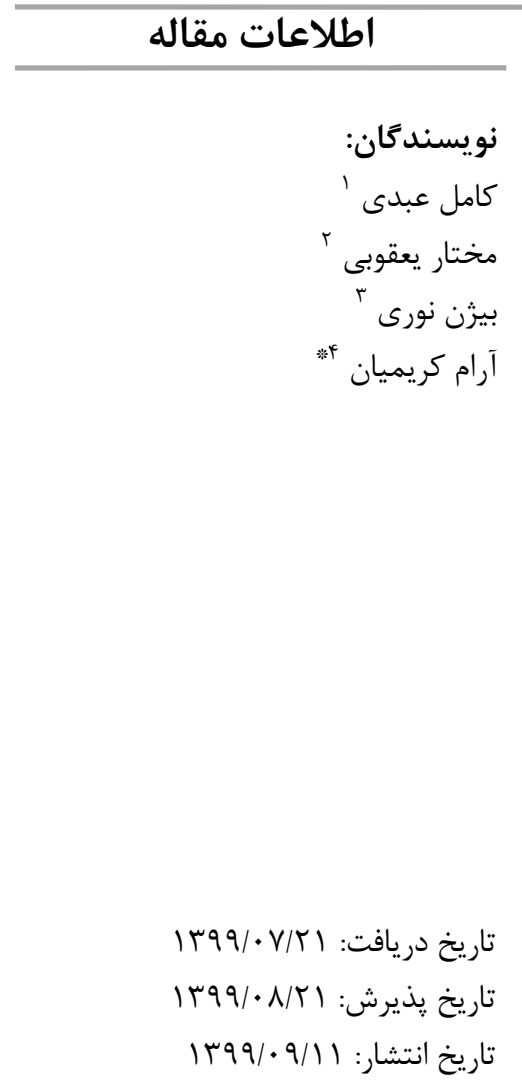

جكيده

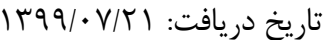

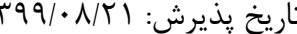

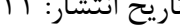

مقدمه: دلبستخى شغلى عاملى موثر در شكلدهى انخيزش كاركنان است و اشتيـاق و و

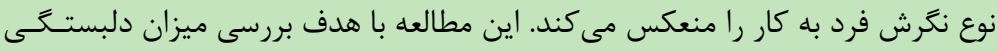

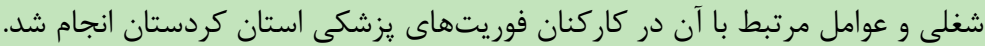

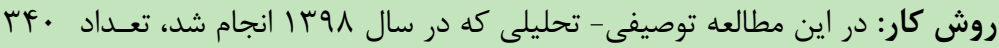

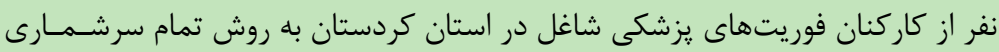

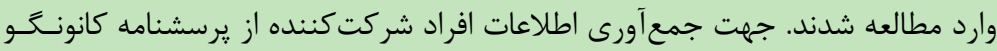

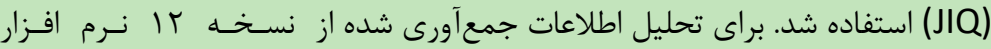

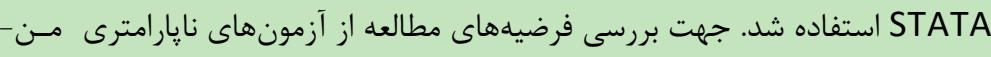

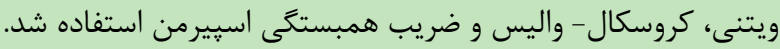

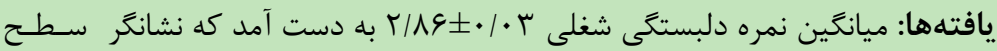

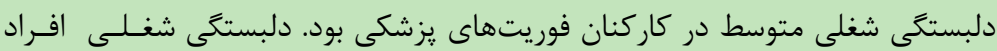

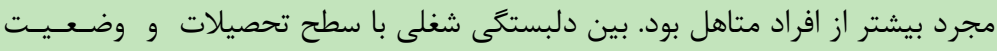

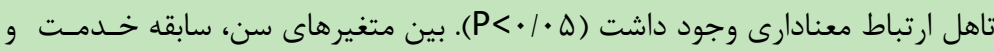

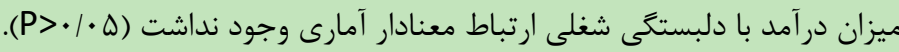

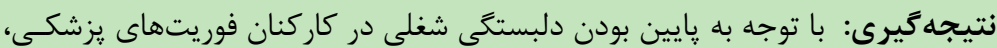

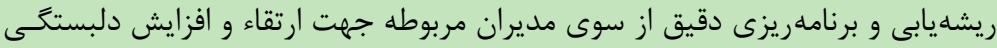
شغلى بيشنهاد مي شود.

\section{وازَّان كليدى: دلبستكى شغلى، فوريتهاى يزشكى، سلامت شغلى}

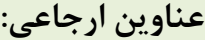

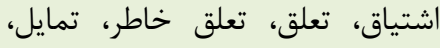

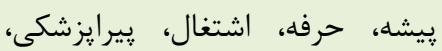
اورزانس
وابستكى سازمانى نويسندكان

ا - كارشناس ارشد يرستارى، كروه يرستارى، دانشكده يزشكى، دانشعاه علوم و تكــــولـوزى كـومـار، سليمانيه، عراق.

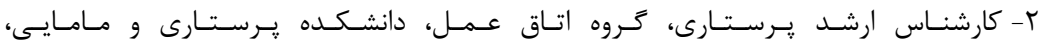
دانشكاهعلوميزشكى كردستان، سنندج، ايران.

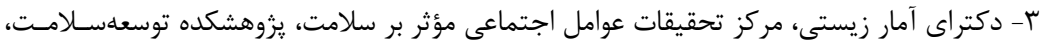

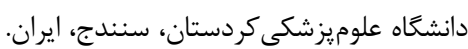

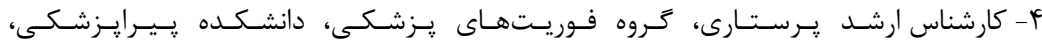

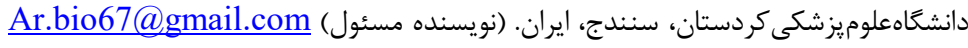


شغلى پايين مى تواند احساس بيكانكَى نسبت به اهداف شغـلـى،

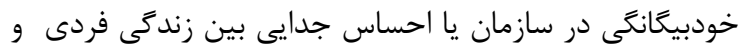

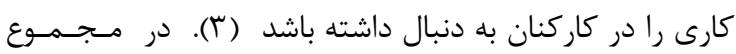

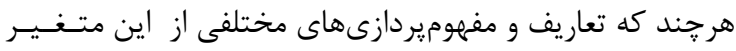

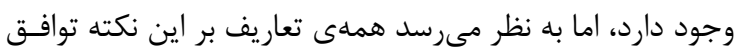

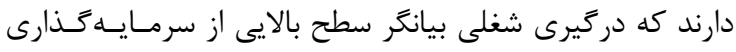

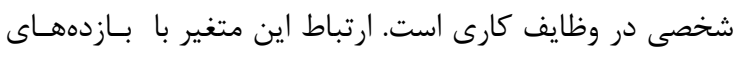

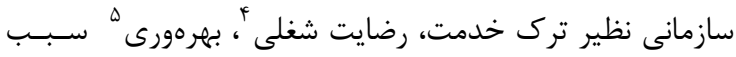

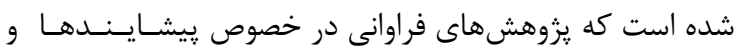

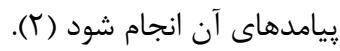

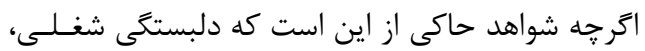

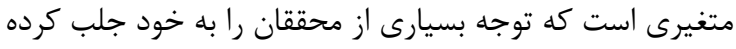

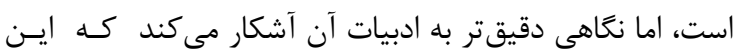

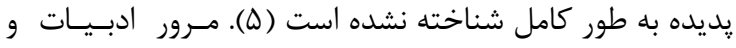

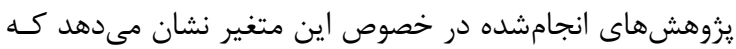

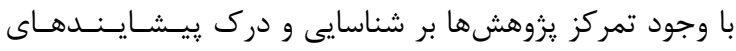

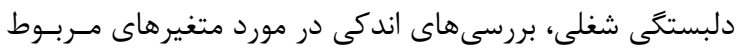

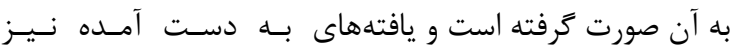

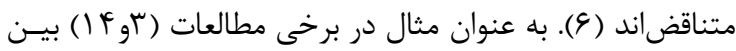

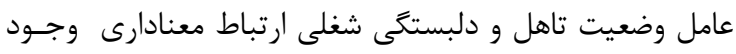

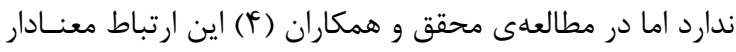

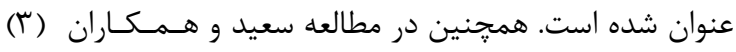

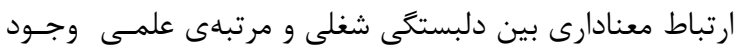

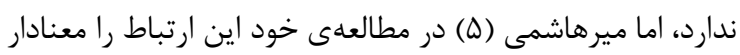

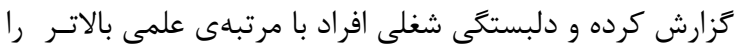
بيشتر عنوان كرده است.

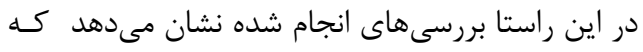

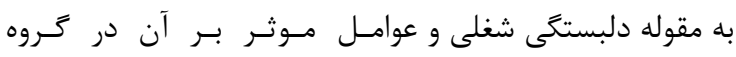
فوريتهاى يزشكى بسيار اندك توجه شده است. از سويى ديخــر

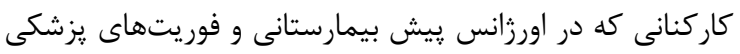

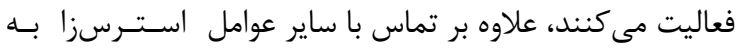

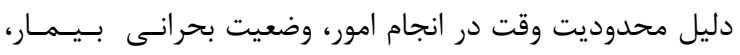

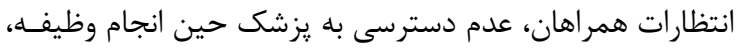

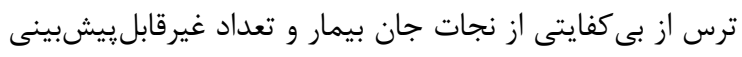

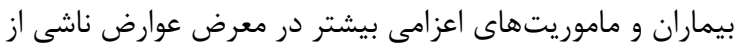

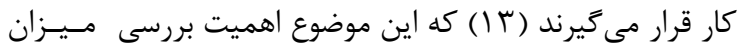

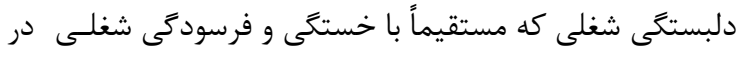

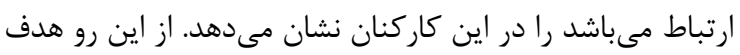

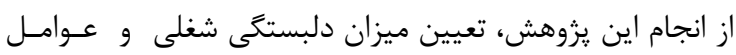

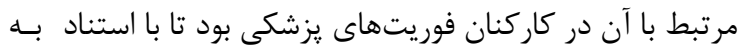

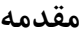

طى دهdهاى اخير، يزوهشگران حوزه روانشناسى سازمـانى و و

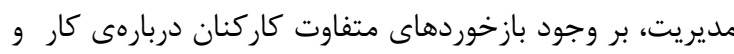

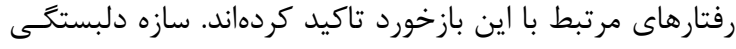

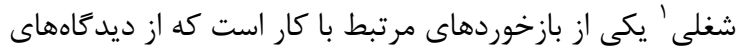

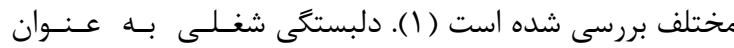

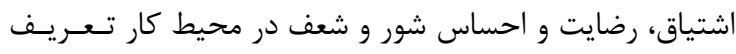

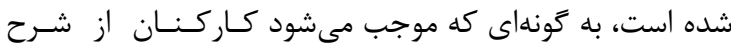

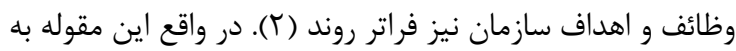

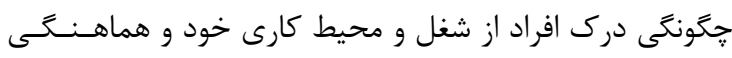
بين شرايط شغلى و زندگى شخصى اشاره دارد (ب).

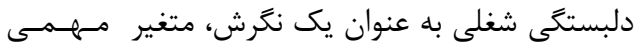

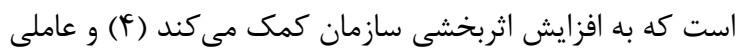

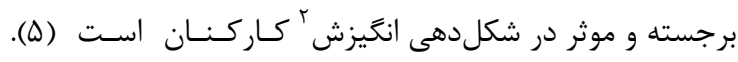

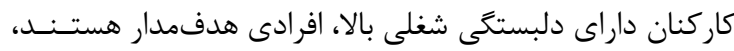

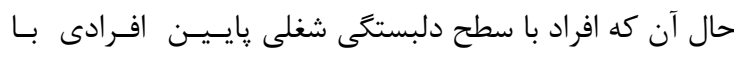

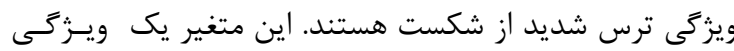
نسبتاً ثابت است كه تحت تاثير وضعيت موجود در محيط كـ كـار

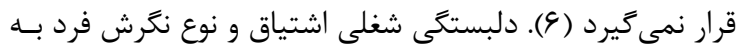

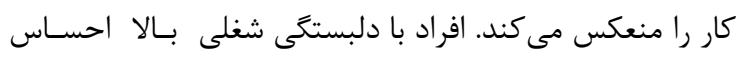

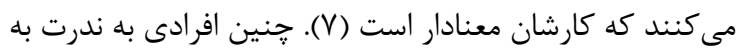

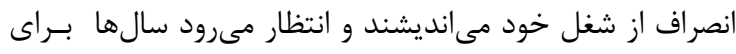

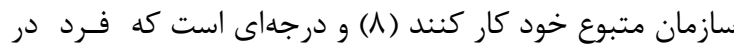

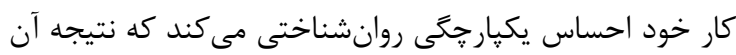

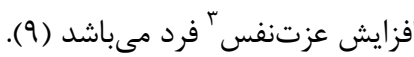

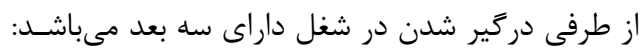

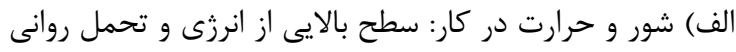

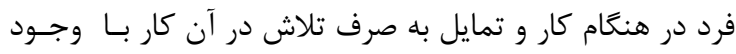

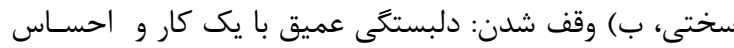

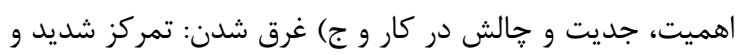

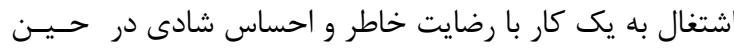

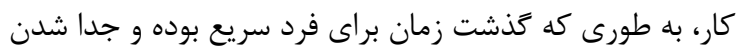

$$
\text { او از كار به سختى صورت مى كيرد (• (1). }
$$

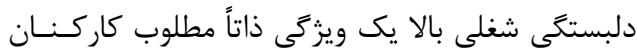

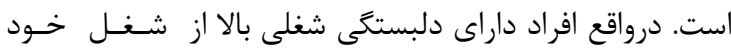

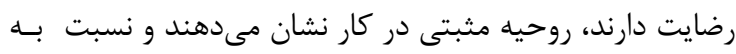

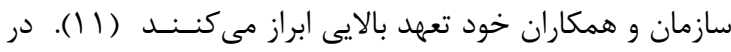

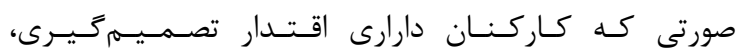

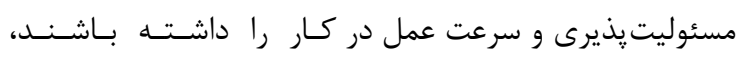

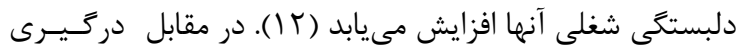

3- Self Esteem 
يرسشنامه در ايران در مطالعات متعددى انـجـام شــده اسـت.

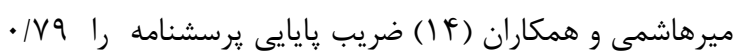

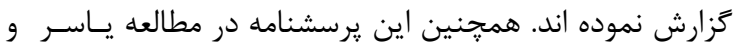

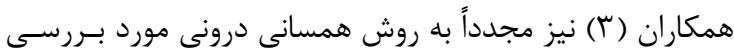

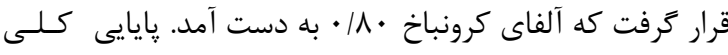

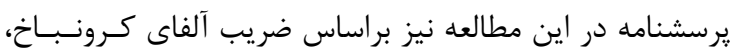

/V9 • محاسبه شد.

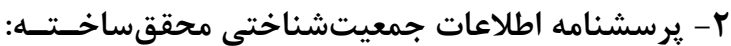

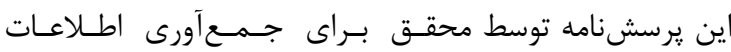

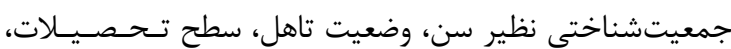
سابقه خدمت، محل خدمت، ميزان درآمد تنظيمى شد. در اين مطالعه براى تحليل اطلاعات جمعآورى شدهن مده داز

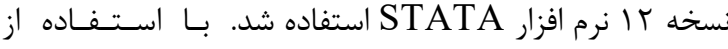
شاخصهاى آمار توصيفى براى متغيرهاى كيفى جدول تـوزيـع

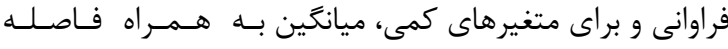

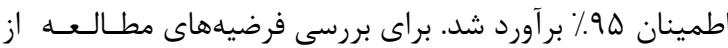

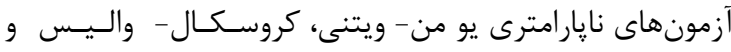

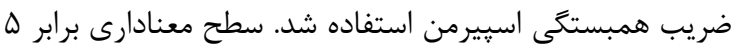
درصد درنظر گرفته شد.

يافتهها

اين مطالعه روى • له نفر از كاركنان فوريتهاى يزشكى استان

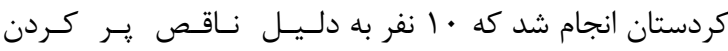

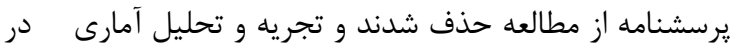

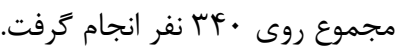

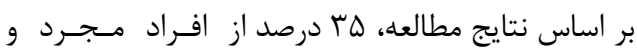

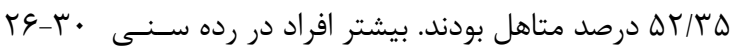

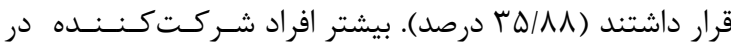
مطالعه سابقه كار كمتر از ه سال داشتند (جدول شماره (1).
نتايج آن بتوان برنامهريزى بهترى جهت بهبود وضعيـت كـارى

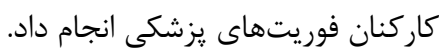

روش كار

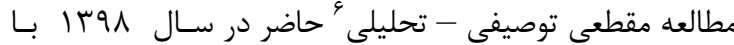

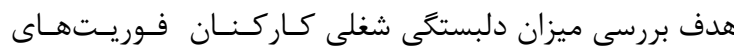

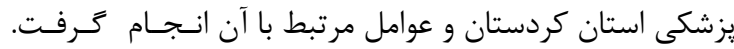

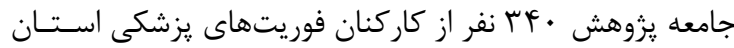

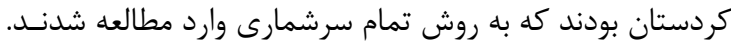

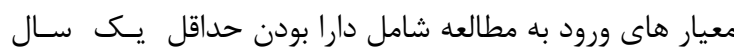

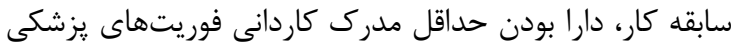

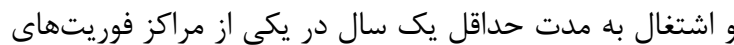

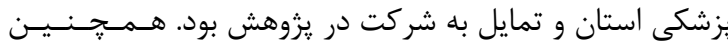
ناقص يرنمودن يرسشنامه، معيار خروج از مطالعه تعيين شد. يس از تاييد يزوهش توسط كميته اخلاق دانشخاه علوم

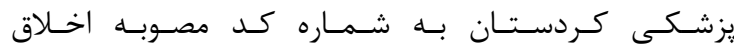

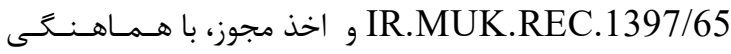
مديران مركز فوريتهاى يزشكى استان كردستان اقدام به انجام

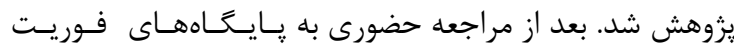

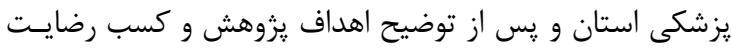

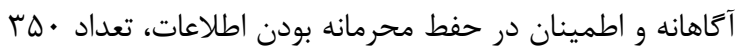
عدد يرسشنامه توزيع شد.

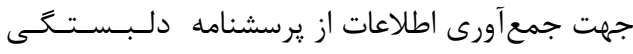

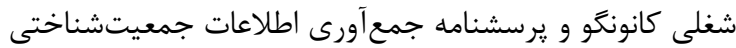
محققساخته استفاده شد.

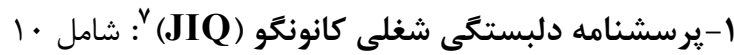

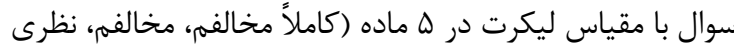

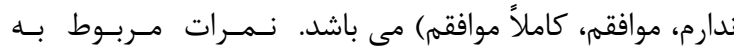

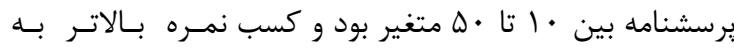

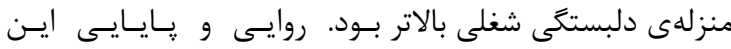

جدول ا: توزيع فراوانى واحدهاى مورد يزوهش بر حسب متغيرهاى جمعيتشناختى و شغلى

\begin{tabular}{|c|c|c|c|}
\hline درصد & 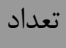 & \multicolumn{2}{|c|}{ متغيرهاى جمعيتشناختى و شغلى } \\
\hline ra & $\Lambda \Delta$ & $r \Delta-r \cdot$ & \\
\hline $\mathrm{r} \omega / \Lambda \Lambda$ & ITt & r.-rG & \\
\hline TN/TY & १९ & ra-r & 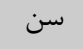 \\
\hline $1 \cdot 1 \mathrm{~A}$ & $r v$ & $r \Delta<$ & \\
\hline FV/Ta & 191 & 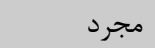 & وضعيت \\
\hline$\Delta T / T \Delta$ & IVq & 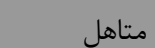 & 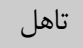 \\
\hline
\end{tabular}




\begin{tabular}{|c|c|c|c|}
\hline rq/vi & Ira & $\Delta>$ & \multirow{4}{*}{ خدمت } \\
\hline re/ve & ITD & $1 \cdot-4$ & \\
\hline $\mid f / q F$ & 81 & $|0-1|$ & \\
\hline$\Delta / \Delta q$ & 19 & $10<$ & \\
\hline TH/TY & vq & سنندج & \multirow{11}{*}{ خدمت } \\
\hline $\mid r / T \Delta$ & Fr & مريوان & \\
\hline$r / 9 \Delta$ & 9 & شويشه & \\
\hline $9 / V 1$ & 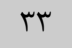 & كامياران & \\
\hline $\mid Q / A \Lambda$ & $\Delta F$ & بيجار & \\
\hline$\Delta$ & iv & قروه & \\
\hline$V / \& \Delta$ & T\& & بانه & \\
\hline $1 / 11$ & f & دهَلان & \\
\hline IN/TF & Gr & سقز & \\
\hline $1 / 11$ & r & وينسار & \\
\hline r/qF & 1. & ديواندره & \\
\hline$r / \cdot \varphi$ & v & دييلم & \multirow{4}{*}{ تحصيلات } \\
\hline$\Delta T / T \Delta$ & IVA & فوق دييلم & \\
\hline Fr/QT & $1 F \wedge$ & كارشناسى & \\
\hline$r / \cdot \varphi$ & v & ارشد و بالاتر & \\
\hline$\Delta F / \Delta$ & $1 \wedge \Delta$ & r - r/Q ميليون & \multirow{2}{*}{ در آمد } \\
\hline$F \Delta / \Delta$ & $1 \Delta \Delta$ & ع/ - ه ميليون & \\
\hline
\end{tabular}

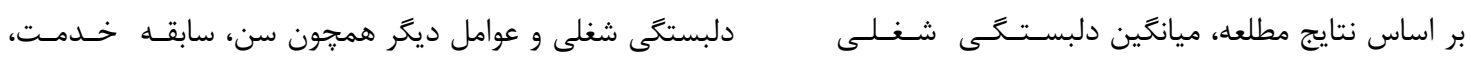

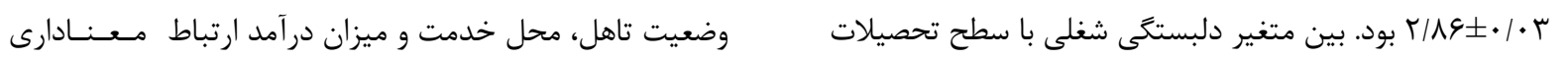

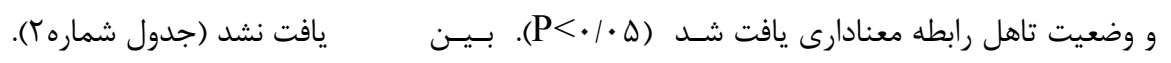

\section{جدول r: متغيرهاى جمعيتشناختى و شغلى، آزمونهاى آمارى و سطح معنادارى متغيرها}

\begin{tabular}{|c|c|c|c|c|}
\hline سطح معنادارى" & آزمون آمارى & ميانگين وابستخى شغلى & اختى و شغلى & متغيرهاء \\
\hline \multirow{4}{*}{$\mathrm{P}=\cdot / / T$} & \multirow{4}{*}{$f=I / \wedge V$} & $r \pm \cdot / \cdot v$ & $r \Delta-r$. & \multirow{4}{*}{ سن } \\
\hline & & $r / \Lambda \pm \cdot / \cdot \Delta$ & $r \cdot-r \varepsilon$ & \\
\hline & & $r / \Lambda \pm \cdot / \cdot \varphi$ & $|r \Delta-r|$ & \\
\hline & & $r / \Lambda \pm \cdot / \cdot q$ & $r \Delta<$ & \\
\hline \multirow{2}{*}{$P=\cdot / \cdot r$} & \multirow{2}{*}{$f=r / r G$} & $r / q T \pm \cdot / \cdot \Delta$ & مجرد & \multirow{2}{*}{ تاهل } \\
\hline & & $r / V q \pm \cdot / \cdot r$ & متاهل & \\
\hline \multirow{4}{*}{$\mathrm{P}=\cdot / r \Lambda$} & \multirow{4}{*}{$f=I / T V$} & $r / \Lambda \pm \cdot / \cdot \Delta$ & $\Delta>$ & \multirow{4}{*}{ خدمت } \\
\hline & & $r / \Lambda \pm \cdot / \cdot \Delta$ & $1 \cdot-9$ & \\
\hline & & $r / q \pm \cdot / \cdot V$ & $|0-1|$ & \\
\hline & & $r / 9 \pm \cdot / \cdot 1$ & $10<$ & \\
\hline
\end{tabular}




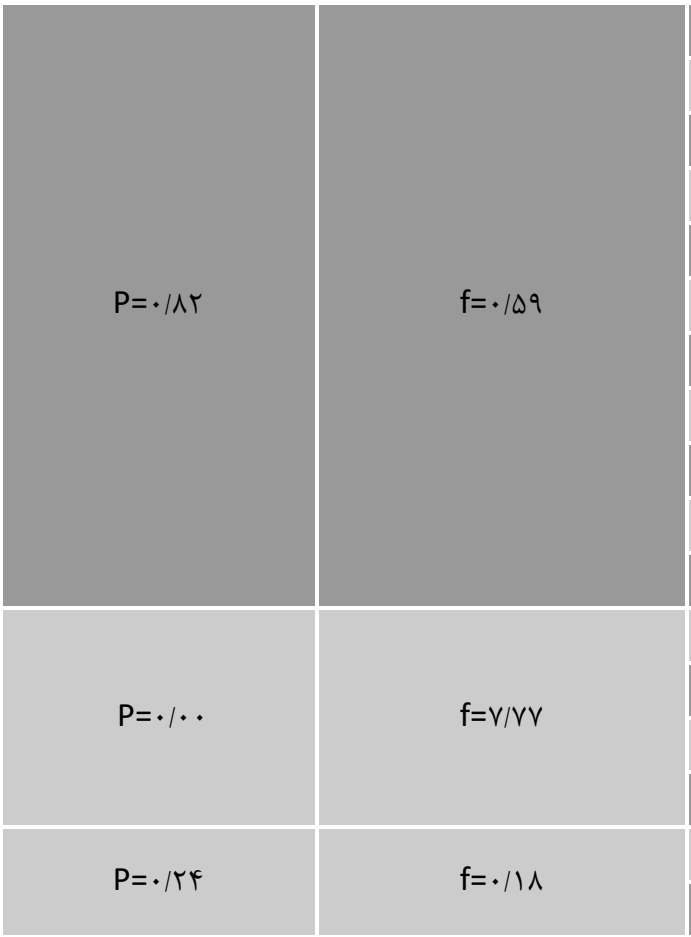

كاركنان عنوان كرد. از سويى ديخر بالا رفتن سطح تحـصـيـلات

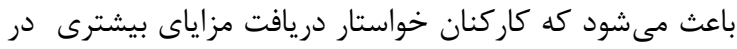

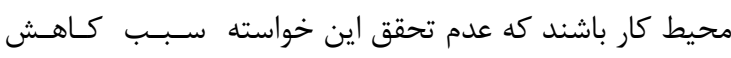

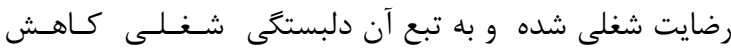
مى ريابد.

از نظر محل خدمت، كمترين دلبستخى شغلى مـربـوط

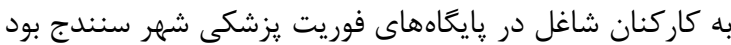

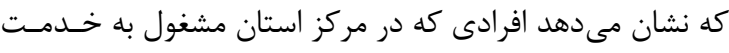

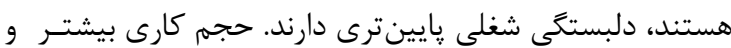

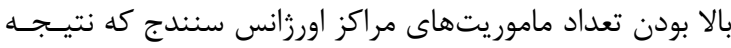

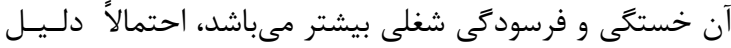

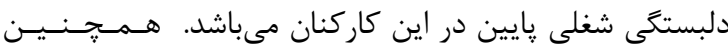

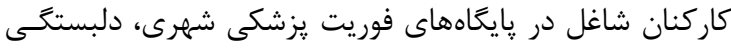

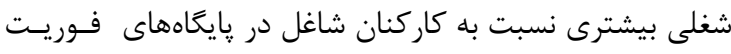

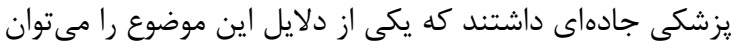

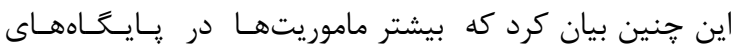

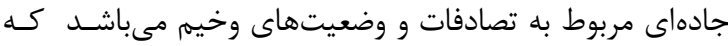

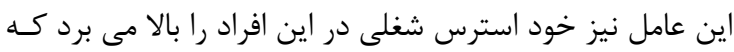

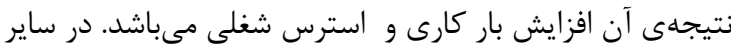

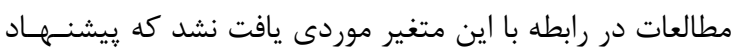
مى گردد مطالعات بعدى در اين زمينه انجام گرددد.

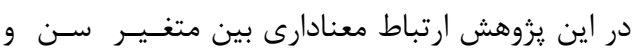

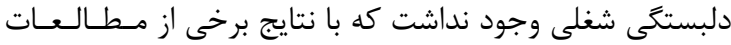

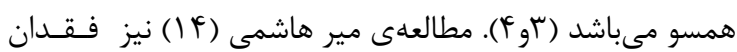

\begin{tabular}{|c|c|c|}
\hline$r / \Lambda \pm \cdot / \cdot V$ & سنندج & \multirow{11}{*}{ خدمت } \\
\hline$r / 9 \pm \cdot / \cdot \Lambda$ & مريوان & \\
\hline$r / \cdot \Delta \pm \cdot / \cdot 1$ & شويشه & \\
\hline$\gamma / \cdot \Lambda \pm \cdot / \cdot 1$ & كامياران & \\
\hline$\gamma / \cdot V \pm \cdot / \cdot q$ & بيجار & \\
\hline$r / q \pm \cdot / \cdot 1$ & قروه & \\
\hline$r / 9 \pm \cdot / \cdot 1$ & بانه & \\
\hline$r / f \pm \cdot / \cdot 1$ & دهكلان & \\
\hline$r / q \pm \cdot / \cdot \Delta$ & سقز & \\
\hline$r / \Lambda \pm \cdot / r$ & وينسار & \\
\hline$r / V \pm \cdot / 1$ & ديواندره & \\
\hline$r / V \pm \cdot / \cdot r$ & ديبلم & \multirow{4}{*}{ تحصيلات } \\
\hline$r / \cdot 1 \pm \cdot / \cdot r$ & فوق دييلم & \\
\hline$r / V \pm \cdot / \cdot F$ & كارشناسى & \\
\hline$r / r \Lambda \pm \cdot / r \Delta$ & ارشد و بالاتر & \\
\hline$r / \Lambda \pm \cdot / \cdot r$ & ه - | | ميليون & \multirow{2}{*}{ در آمد } \\
\hline$r / \Lambda \pm \cdot / \cdot 1$ & $\Delta-r / \varphi$ & \\
\hline
\end{tabular}

\section{بحث و نتيجه}

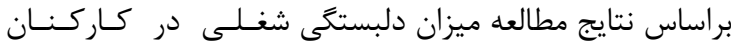

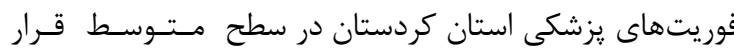
داشت. نتايج اين بخش از مطالعه با نتايج مطالعهى ياسر سعيد درديد

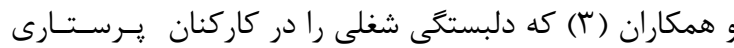

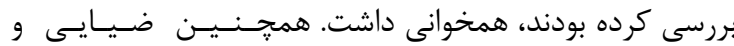

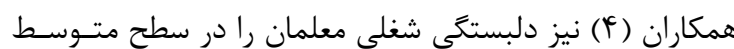

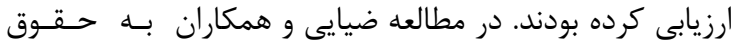

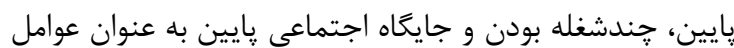

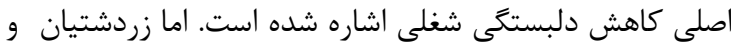

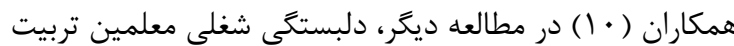

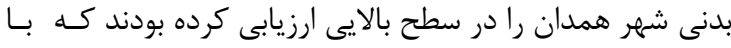

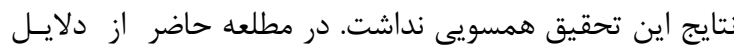

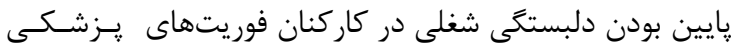

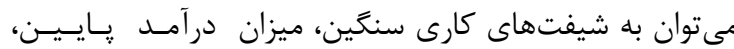

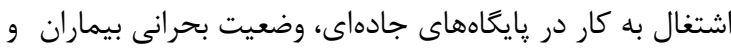
استرس كارى بالا اشاره كرد.

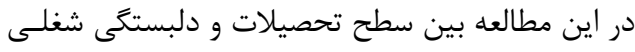

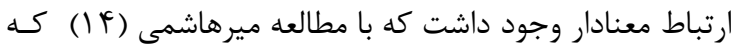

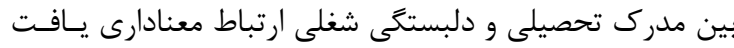

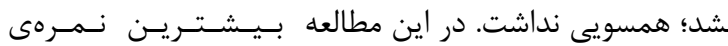

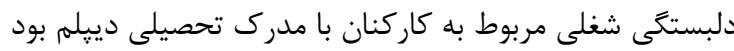

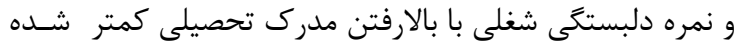

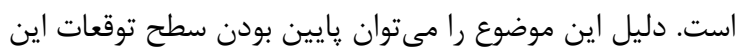




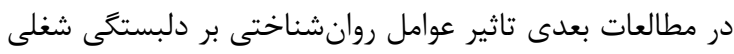

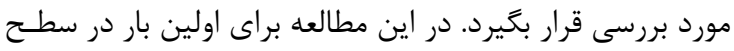

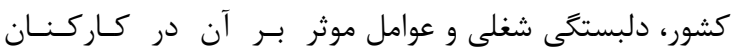

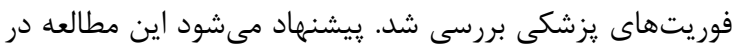

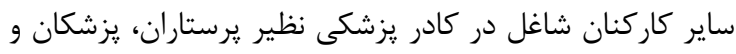

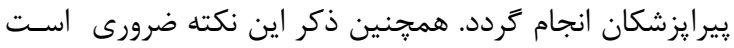

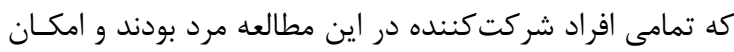

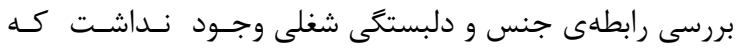

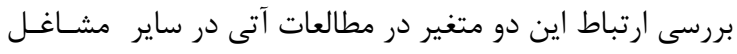

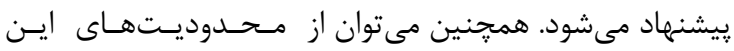

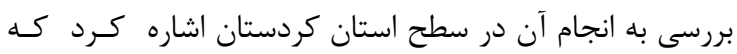

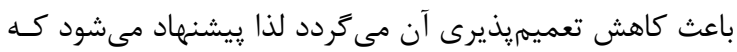

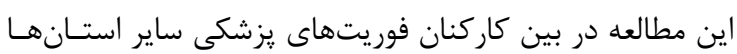

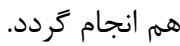

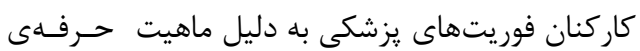

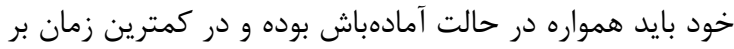

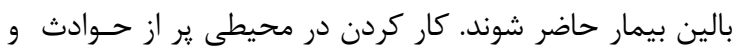

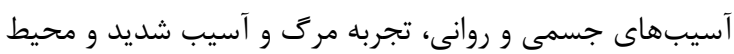

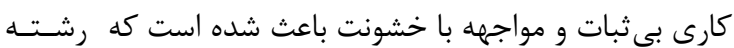

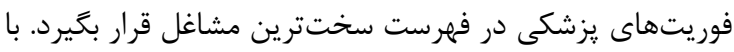

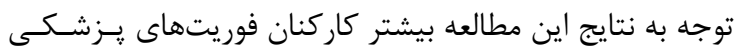

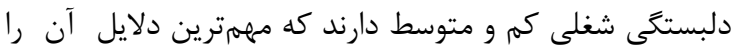

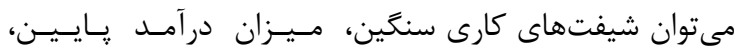

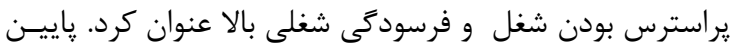

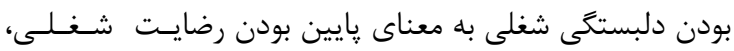

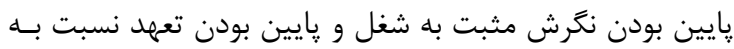

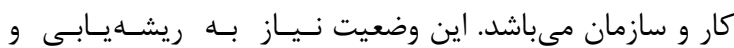
برنامهريزى دقيق از سوى مديران مربوطه جهت ارتقاء إنقاء و افزايش دالبستكى شغلى دارد.

\section{تشكر و قدردانى}

IR.MUK.REC.1397/65 اين مطالعه با كد مصوبه اخلاق

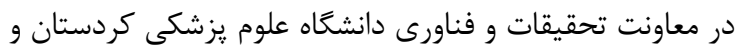
كميته اخلاق دانشخاه تصويب شده است. نويسندكان اين مقالـاته از حمايت ها و همكارى معاونت تحقيقات و فنـاورى دانش دانشعـاه

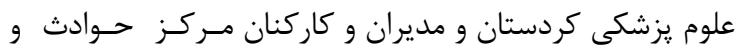

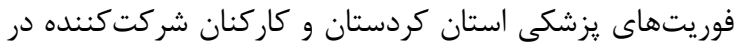
اين مطالعه، كمال تشكر را دارند.

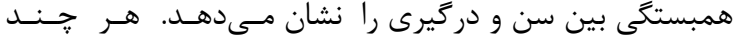

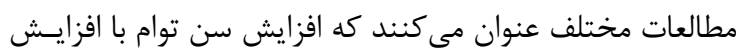

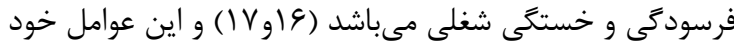

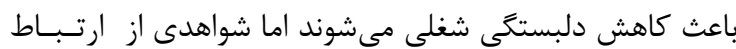
بين سن و دلبستكى شغلى موجود نيست.

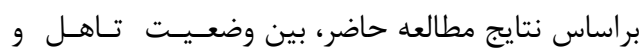

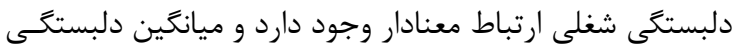

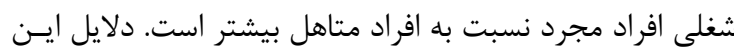

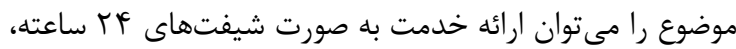

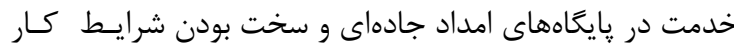

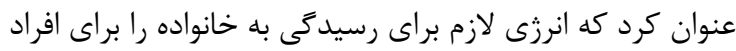

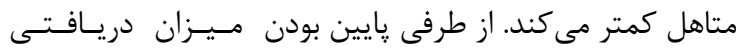

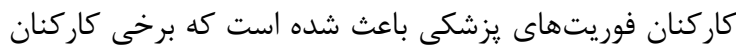

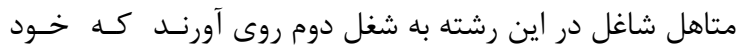

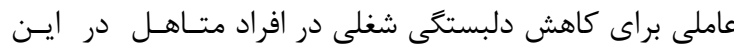

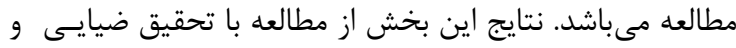

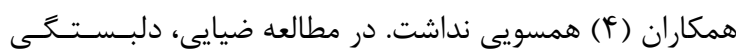

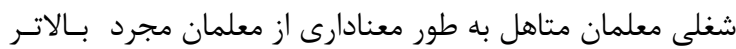

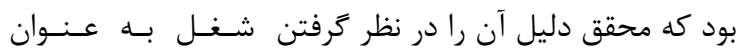

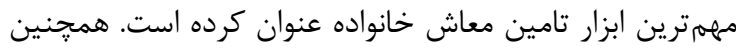

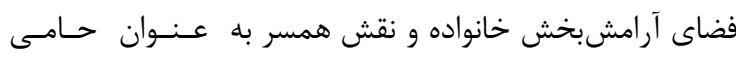

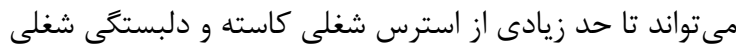

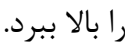

بين سابقه كار و دلبستكى شغلى ارتباط معنادار وجـود

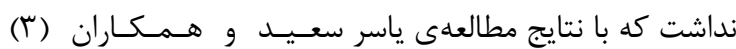

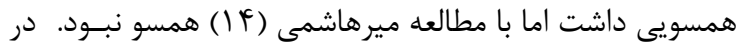
مطالعه ميرهاشمى عنوان شده است با توجه به اين كه افئ افزايـش

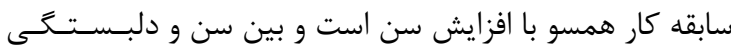

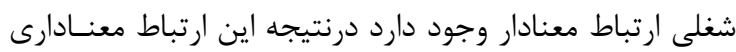

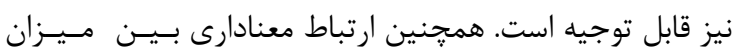

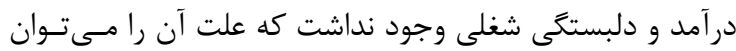

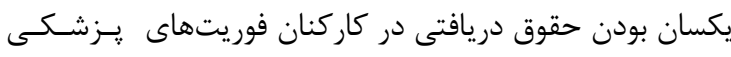

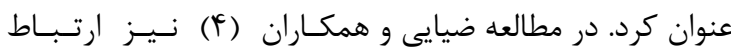

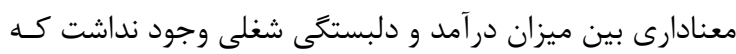

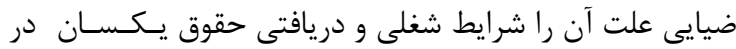
افراد با سطح تحصيلات متفاوت عنوان كرده است دان.

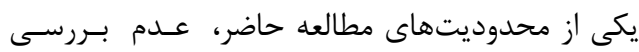

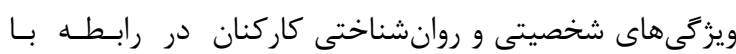

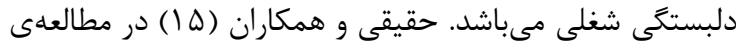

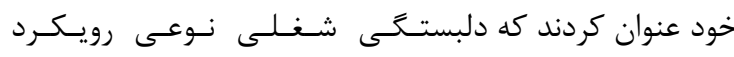
روانشناختى نسبت به شغل مى باشد و عوامل روانى نظير عاطفه

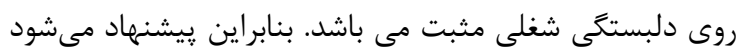




\section{References}

1- Moafimadani SM,Teymourzadeh V.Study of Relationship between Emotional Intelligence and Job Involvement in Future Management. J Manag Syst. 2015;23(4):65-74.

2- Shahmohammadi A, Ardalan MR, Zandi K, Seifpanahi H, Feizi K. Relationship between Spiritual Leadership and Job Engagement: A Case Study of Kurdistan University Employees. J Hum Resour Manag. 2015;5(17):135-56.

3- Yaser S, Tabanejad Z, Nahrir B, Ebadi A, Khoshab H, Babajani S. The relationship between job involvement and demographic characteristics in nurses in hospitals of Tehran and Kerman in 2013. J Clin Nurs Midwifery. 2014;3(4):39-46.

4- Ziaei M, Rezaei G, Yarmohammadi H, Khoshboo E, Gharagozlou F. The relationship between teachers' job involvement and demographic characteristics in Dalahou (Kermanshah) secondary schools in 2013 Downloaded. J Ergon. 2015;3(1).

5- Mirhashemi M, Hanafi K. The relationship between entrepreneurship and job involvement among staff of Islamic Azad University Roudehen ranch. Mod Thoughts Educ. 2012;7(1):41-58.

6- Karimzadeh Z. Predicting Job Involvement of IAU Faculty Members based on their Philosophical Mind-Set (A Case Study in Roudehen Branch of IAU). J Mod Thoughts Educ. 2013;8(2):82-92.

7- Wang M-L, Chang S-C. The Impact of Job Involvement on Emotional Labor to CustomerOriented Behavior: An Empirical Study of Hospital Nurses. J Nurs Res. 2016;24(2):153-62.

8- Khalesi N, Salehi M, Moradi F, Ahadinezhad B, Mohammadi R, Rohani B. The Relationship between Servant Leadership and Job Involvement of staff in Teaching Hospitals Affiliated to Kurdistan University of Medical Sciences: 2011. J Heal Adm. 2012;15(47):23-32.

9- Song J, Lee N, Park S. The Influence of Verbal Aggression on Job Involvement and Turnover Intention in Organizational System. 2015;4(2):54-60. 10- Zardoshtiyan S, Abbasi H, Esmaeili M, Khanmoradi S. The Relationship Perceived Organizational Support, Job Involvement and Organizational Citizenship Behavior of Physical Education Teachers in Hamedan Province. Organ Behav Manag Sport Stud. 2015;2(6):93-103.

11- Kalantari M, Ghorchian N, Sharifi HP, Jafari P. A model to promote managers job involvement in islamic azad university based on cognitive styles, locus of control and leadership styles. J Mod THOUGHTS Educ. 2011;6(2):123-40.

12- Ravangard R, Mohamadi Z, Sajjadnia Z, Ghanavatinejad Z. Nurses' Job Involvement and Their Personality Traits in Teaching Hospitals Affiliated to Shiraz University of Medical Sciences, 2013. Heal Scope. 2014;3(1):1-5.

13- Rezaeironaghi J, Paravar M, Rezaei M, Ebrahimi H. Relationship between Burnout and Social Support in Emergency Medical Personnel in Kashan City. J Knowl Heal. 2017;11(4):63-72.

14- Mirhashemi M, Predictors of job involvement among faculty.Developmental psychology.2008;4 (15):235-44.
15- Haghighi A, Haghighi S, Samavatian H, Amini M, Abasi Hafshejani M. Predicting job involvement through positive affect and emotional quotient among midwives and nurses. Iranian Journal of Obstetrics, Gynecology \& Infertility. 2012; 15 (30): 22-28.

16- Rouhi Gh ARH, Nasiri H, Balou Z Mahmoudi Gh. Job burnout and its relation to nurses' attitude relation to salary and benefit of nurses' staff in hospitals depend on Golestan University of Medical Sciences during2007. Journal of Research Development in Nursing and Midwifery 4(1)2007.

17- Baraz PS, Karimipour F, Ebrahimi DM. Evaluation of the relationship between self-esteem and burnout in nurses of hospitals of Ahvaz Jundishapur University of Medical Sciences. Iranian journal of nursing research. 2013; 7(27): 44-51. 